Research Square
Preprints are preliminary reports that have not undergone peer review.

They should not be considered conclusive, used to inform clinical practice, or referenced by the media as validated information.

\title{
Genetic Diversity and Population Structure in Wild Seabuckthorn (Hippophae Salicifolia) Growing in the Uttarakhand Region of The Indian Himalayas
}

\author{
Parneeta Chaudhary \\ Guru Gobind Singh Indraprastha University \\ Prakash Chand Sharma ( $\nabla$ prof.pcsharma@gmail.com) \\ Guru Gobind Singh Indraprastha University https://orcid.org/0000-0002-7939-4780
}

\section{Research Article}

Keywords: Seabuckthorn, Hippophae salicifolia, Microsatellite markers, Genetic Diversity, UPGMA

Posted Date: November 8th, 2021

DOI: https://doi.org/10.21203/rs.3.rs-982370/v1

License: (9) (1) This work is licensed under a Creative Commons Attribution 4.0 International License. Read Full License 


\section{Abstract}

Seabuckthorn (Hippophae salicifolia) is an economically important dioecious and deciduous actinorhizal tree species. Considering the contemporary interest in seabuckthorn as a future multipurpose crop, efforts have been initiated towards an assessment of genetic diversity prevailing in the natural populations inhabiting diverse geographical areas. In the present study, morphological and molecular diversity was studied in Hippophae salicifolia representing diverse ecological sites in the different geographical areas of the Garhwal and Kumaon regions of Uttarakhand, India. Morphological diversity was assessed by studying a total of twenty-seven morphological characters. For standard identification of the color of leaves and berries, a color-coded reference (RHS)-based study was also performed. By employing fifteen microsatellite markers, we observed 109 alleles, with $71.5 \%$ markers being polymorphic. Furthermore, Polymorphic Information Content $(0.387)$, expected heterozygosity $\left(H_{e}\right) /$ Nei's Diversity $(0.641)$, Wright's fixation index $\left(F_{i s}\right)$ (0.630), and Shannon's informative index (I) (0.646) among the four populations were calculated simultaneously to study the phylogenetic relationship. The UPGMA-based dendrograms were also prepared by using morphological and molecular data. The dendrograms showed a demarcation between collections from different regions, although a few collections were found clustered with collections from the other regions. Assessment of genetic diversity was efficient and more informative using microsatellite markers. The findings of this study will be useful in future breeding and conservation programs in Hippophae salicifolia and related species.

\section{Introduction}

Seabuckthorn (H. salicifolia) is a dioecious and deciduous, woody shrub-to-tree habit species found growing in the semi-arid high altitudes of the Indian Himalayan regions. The plant has an extraordinary capacity to grow and sustain different abiotic stresses, particularly temperature stress. The plant also has a unique subterranean root system with a firm soil binding ability for soil stabilization and water retention that helps in managing several ecological problems in mountain areas (Lu 1992). Moreover, seabuckthorn is a storehouse for a number of useful bioactives with immense medicinal, pharmaceutical, and nutraceutical properties.

Three species of the genus Hippophae viz. H. rhamnoides, $H$. salicifolia, and $H$. tibetana are found growing wild in the different regions of the Indian Himalayas. H. rhamnoides, the most common species, is prevalent in the Union Territory of Ladakh, and Himachal Pradesh, $H$. salcifolia grows in Uttarakhand, Sikkim, and Arunachal Pradesh, and H. tibetana is scarcely found in some regions of the Indian Himalayas (Dwivedi et al. 2009). H. salicifolia is less-thorny to completely thorn-less and bears yellow-orange spherical berries that are rich in essential polyunsaturated fatty acids, antioxidants, and minerals (Suryakumar and Gupta 2011). Seabuckthorn is also well known to possess anti-cancer, anti-inflammation, anti-radiation, anti-ageing, antioxidative properties and is beneficial in treating cardiovascular diseases, skin-related problems, bowel issues, and burns (Teng et al. 2006).

Stands of $\mathrm{H}$. salicifolia are found growing in the natural habitats of Garhwal and Kumaon regions of Uttarakhand, where the berries of the plant are harvested for their nutritional contents. The berries and leaves of $\mathrm{H}$. salicifolia are traditionally consumed for centuries by the local population and the species has attracted the attention of the cultivators as an important species for domestication (Akulinin1958; Ge et al. 1985). Thus, with the increasing demand for seabuckthorn berries, the exploitation of the plants has multiplied substantially.

Considerable morphological variations can be witnessed in the shape, size, and color of the fruits, and leaves of wild seabuckthorn germplasm (Rousi 1971; Zhao et al. 1997; Lian et al. 2003). A number of elaborate studies are conducted on the genetic diversity of seabuckthorn, notably on H. rhamnoides, however, the species H. salicifolia has remained unexplored (Yao and Tigerstedt 1993; Sun et al. 2006). These studies suggest that the variations on the morphological, biochemical, and molecular levels are controlled by a combination of biotic and abiotic factors (Nawaz et al. 2018). Therefore, research on the molecular discrepancy of the seabuckthorn population in the Indian trans-Himalayan region will help to characterize and understand the level of genetic diversity present in the ecotypes of seabuckthorn (Srihari et al. 2013).

The microsatellite markers have been the most simplest and reliable used molecular markers for the characterization of genetic diversity, and have a number of other applications such as genome mapping, gene tagging, parentage analysis, phylogenetics, and molecular ecology (Li et al. 2009). These markers are considered advantageous compared to other molecular markers by virtue of their hyper-variability, abundance, co-dominance, reproducibility, and easy detection assay (Grover and Sharma 2016). This study employed microsatellite markers to investigate the genetic diversity among 100 genotypes representing four geographically diverse populations of $\mathrm{H}$. salicifolia collected from natural strands growing in the Uttarkashi, Chamoli, and Pithoragarh districts of Uttarakhand in the Indian Himalayan region. The study was aimed to have a better knowledge of population structure and generate important data useful for the conservation, selection, and breeding of the species.

\section{Materials And Methods}

Plant material and sampling area

H. salcifolia leaf samples from 17 different sites were collected from four distinct geographic regions (considered as four populations in this study) of Yamunotri and Gangotri (Uttarkashi) Badrinath (Chamoli) of Garhwal division, and Munsyari (Pithoragarh) of Kumaon division of Uttarakhand (Fig. 1). Each geographical location was at a minimum distance of $5 \mathrm{Km}$ from the neighboring collection site and was considered to have variations in terms of altitude, water availability, and exposure to sunlight, temperature and precipitation variations, and soil type. Collections were made during September 2019 (Uttarkashi and Chamoli) and November 2020 (Pithoragarh). Sampled plants were geographically tagged using a GPS device (Garmin-eTrex 30) and the details are summarized in Table 1. The samples were labeled after documenting various phenotypic characters of the individual plant and stored in icepacks for transportation to the laboratory. The leaves were further stored in -80凶C for further use. 
Morphometric analysis

A total of twenty-seven morphological characteristics were recorded by randomly selecting ten leaves, fruits, and thorns from each individual plant considered for sample collection. The color of leaves tissue (dorsal and ventral side) and berries were determined by an effective method of 920 RHS colorcoded reference from 'The Royal Horticultural Society' (RHS) color charts. The 920 RHS color-coded references are decoded into the Red-Green-Blue (RGB) standard colors used for a visual representation to identify plant tissue colors (Nawaz et al. 2018). It is freely available on the RHS webpage (http://rhscf.orffree.com) and was accessed on March 3, 2020).

Extraction of plant genomic DNA

Genomic DNA from young leaves of $H$. salicifolia, collected from the different regions of Uttarakhand, was isolated following the CTAB based protocol (Doyle and Doyle 1990) with certain modifications. The use of PVPP 1.5\% Polyvinylpolypyrrolidone (PVPP) and enhanced concentrations of $\beta$ mercaptoethanol ( $2 \%$ ) was found suitable for good yield as well as high quality of genomic DNA (Jain, 2015). DNA concentration and quality were checked at $1.0 \%(\mathrm{w} / \mathrm{v})$ agarose gel (containing $6 \mu \mathrm{l}$ of $\mathrm{EtBr}(10 \mathrm{mg} / \mathrm{ml}))$ in $120 \mathrm{ml}$ of $1 \mathrm{X}$ TAE buffer by electrophoresis using $\lambda($ lambda) DNA as a reference. The genomic DNA equated to $25 \mathrm{ng} / \mu \mathrm{l}$ concentration was considered for further use.

Primer designing, validation of primers, and allele detection

Randomly selected microsatellite positive sequences from the seabuckthorn transcriptome (Ghangal et al. 2013; Jain et al. 2013) were used to design primers for the flanking regions of microsatellite loci. Sixteen primer pairs were designed with the help of software Primer3 (http://primer3.wi.mit.edu/) (Rozen et al. 2012) (Table 2). Primer pairs designed by Jain et al. (2013) from microsatellite positive sequences from genomic libraries, EST database were also screened in the present study. The parameters considered for the primer design were $45-55 \% \mathrm{GC}$ content, $18-22 \mathrm{bp}$ length, and $50-60{ }^{\circ} \mathrm{C}$ annealing temperature. A $25 \mu \mathrm{l}$ PCR reaction was set up containing 10pmol of each synthesized primer pair (forward and reverse each), $100 \mathrm{mM}$ of dNTPs mix, 1.5 $\mathrm{mM} \mathrm{MgCl}_{2}, 0.5 \mathrm{U}$ of Taq polymerase (Go Taq Promega), and $1 \mu \mathrm{l}(50 \mathrm{ng})$ of genomic DNA. Amplifications were carried out in a Mastercycler (Eppendorf, Germany) with a PCR regime having 5 min of pre-amplification denaturation at 95区C, followed by 35 cycles of $30 \mathrm{~s}$ at $95 \rrbracket C$, $30 \mathrm{~s}$ at annealing temperature (primer-specific), and $40 \mathrm{~s}$ at 72खC. As the final step, products were kept for $5 \mathrm{~min}$ at $72 \varangle \mathrm{C}$ and then stored at $4 \llbracket \mathrm{C}$ until further use. The amplified PCR products were resolved by electrophoresis on $3 \%$ agarose in 1 X TAE buffer solution. The amplicons were visualized and recorded using a gel documentation system (Alpha Imaging). Further, the presence and absence of each allele was manually scored as 1 (presence) and 0 (absence) and included in a binary data matrix in MS-Excel.

Statistical analysis

The binary data matrix recorded for the presence and absence of allele for all individual microsatellite loci were further analyzed using GenAlex software (Peakall and Smouse 2006). Analysis of molecular variance (AMOVA), $F_{\text {ST }}$ estimation, $F$-statistics, mean heterozygosity calculation, Nei's genetic similarity and differences estimation, and genetic distance was performed using the PAST4 v 4.07. A dendrogram was generated using Jaccard's coefficient and UPGMA cluster analysis in PAST4 v 4.07 based on the morphometric characters recorded for $H$. salicifolia collections. We also performed a cluster analysis based on Nei's genetic similarity matrix among the four populations of $H$. salicifolia collection from different geographical regions, following Nei and Li (1979). POPGENE v 1.32 (Yeh and Boyle 1997) was used to evaluate other parameters such as PIC (Polymorphism Information Content), Nei's gene diversity $\left(\mathrm{H}_{\mathrm{e}}\right)$, Shannon's information index $(\mathrm{I})$, Wright's Fixation Index $\left(\mathrm{F}_{\mathrm{is}}\right)$, the effective number of allele $\left(\mathrm{N}_{\mathrm{e}}\right)$, and the observed number of allele $\left(\mathrm{N}_{\mathrm{a}}\right)$.

\section{Results And Discussion}

Plant material and sampling area

The Indian Himalayas are home to three species of seabuckthorn, a medicinally and ecologically important plant, namely $H$. rhamnoides, $H$. salicifolia, and H. tibetana. In India, H. salicifolia is primarily distributed in Garhwal and Kumaon divisions of Uttarakhand, Tawang region of Arunachal Pradesh, and sparse populations exist in Kinnaur district of Sangla valley in Himachal Pradesh. In the present study, 100 samples, constituting four populations, were collected from four regions of Garhwal and Kumaon divisions of Uttarakhand and analysed for the presence of genetic diversity prevailing in these regions. Human invasive activities and changing environmental conditions may result in the genetic loss of important alleles of seabuckthorn in near future. Hence, similar to other plant species, conservation and scientific exploration of genetic diversity is necessary for seabuckthorn improvement (Berding and Roach 1987; Lian and Chen 2000).

Morphometric analysis

We considered twenty-seven previously described morphological features (Singh et al 2003) to discriminate the $H$. salicifolia collections from four different geographical regions of Uttarakhand. The average plant height was $470 \mathrm{~cm}$ with an individual minimum and maximum of 133 and $489 \mathrm{~cm}$, respectively, while the canopy area was averaged at $8.21 \mathrm{~m}^{2}$ (Range: 2.29-3.88 $\mathrm{m}^{2}$ ) (Table 3). It was observed that collections from Uttarkashi (Yamunotri and Gangotri) had little to no thorns; otherwise, no branching of thorns was observed. The upper leaf surface of the samples collected was found to be a smooth surface in all Uttarakhand collections (Supplementary Table S1). Another contrasting feature was the occurrence of silver scales on leaves, a prominent feature of $H$. rhamnoides growing in Ladakh, which was a completely absent trait in all the collections of $H$. salicifolia from Uttarakhand. All above-listed features contributed markedly towards variation in phenotypic diversity between the collections sets from different regions of Uttarakhand. 
Morphological features like stem shape, stellate hairiness on young branches, number of leaves attached to a single point, stellate hairs beneath leaves, and color of the dorsal surface of the leaf did not show any significant variation among the collection sets (Supplementary Table S1). It was observed that in the majority of the collections, mature stem color was observed to be brown, whereas immature stem color was reddish-brown. The possible reason for this observation could be the late accumulation of secondary metabolites in Uttarakhand collections, which could be a geographical area-specific characteristic. Twenty morphological features were classified into various ordinal categories represented by a number, and model values were calculated to assign the characteristic representative qualitative trait (Supplementary Table S1). Similar expression of morphological characteristics has been observed in the previous studies conducted over H. rhamnoides collections representing different geographical regions (Singh 2002; Singh et al. 2005; Singh 2014).

Out of the twenty-seven characters studied, sixteen could be measured as metric traits, and marked variations were observed among collections representing the different geographical areas (Table 3). In comparison with the previous studies, present values commensurate with observations made on H. rhamnoides but differed from those observed in H. salicifolia (Singh 2002, 2014; Singh et al. 2005). Plant height was also found to vary significantly among the collections (range 133-489 cm, average $290 \mathrm{~cm}$ ).

Leaf length and leaf width also reduced with an increase in altitude. Similar variations as observed in the case of canopy width and plant height with respect to altitude variations. However, inter-branch distance, degree of thorniness, and leafiness were found significantly higher in lower altitude regions. Furthermore, only $5.01 \%$ of $\mathrm{H}$. salicifolia (Yamunotri) Uttarkashi population of Uttarakhand had thorns (Table 3 ). Substantial variation was observed in the leaf traits among the collections from Garhwal and Kumaon division of Uttarakhand (Table 3). Leaf area ( $\mathrm{mm}^{2}$ ) was observed to be higher in regions with lower altitudes (Uttarkashi regions are lower in altitude than Chamoli and Pithoragarh). Moreover, a significant positive correlation was observed to exist between leaf area and altitude, leaf area decreased with an increase in altitude (Higher the altitude, lower the leaf area). The observation of the leaf length to leaf width ratio showed that the widest $(7.7 \mathrm{~mm}$ ) leaves were found in (Gangotri) Uttarkashi population and narrowest (6.9 mm) in the (Munsyari) Pithoragarh region of Uttarakhand. Leaf area was also recorded higher in collection sites near the villages and cultivated lands that might be due to unintentional management of the plants via irrigation or/and better nutrition near cultivated fields. The leaf and fruit size respond to such treatments; hence, the reason for a better volume of leaf and fruits might be due to these factors.

The maximum and minimum weight of 20 berries was recorded as $5.18 \mathrm{~g}$ and $3.10 \mathrm{~g}$, respectively. Substantial variation exists in all fruit traits among the populations. Fruit volume $\left(\mathrm{mm}^{2}\right)$ was also highest $\left(1.9 \mathrm{~mm}^{2}\right)$ in collections from Uttarkashi (Yamunotri and Gangotri region) and lowest (1.4 mm $\left.{ }^{2}\right)$ in the collections from (Munsyari) Pithoragarh. The leaf and fruit morphometric characters were observed to have similar variations in all the collections (lower values in the Pithoragarh region as compared to Chamoli and Uttarkashi regions) (Table 3).

Substantial variations were observed for leaf color (ventral and dorsal) and fruit color among all the collections of four populations (Supplementary Fig. S1). It was observed that for the fruit color most common shades in all samples were N25D and 22A (25.9\%). Three rare colors coded; $26 \mathrm{~A}$, $15 \mathrm{~A}$, $17 \mathrm{~A}$ (14.2\%) were more common in Chamoli (Gangotri) region (Supplementary Fig. S1). Moreover, it was observed that four RHS color shades were common in the ventral side of leaf, whereas only one rare color was observed. Similarly, eight RHS shades were dominant in the dorsal side of the leaf with only two rare colors in all the collections. Color richness was significantly higher in the collections from the Yamunotri region than in the Badrinath region, whereas it was observed that differences were significantly less within-population.

This was the first time, the RHS charts references were used for $H$. salicifolia leaf and fruits color assessments in India. This tool was earlier used by Nawaz et al. (2018) in the assessment of $H$. rhamnoides growing in the Karakoram Mountains. The assessment of the color shades is challenging as the shades of color highly depend upon the maturity stage, sunlight exposure, availability of water, soil nutrient, and also natural calamities that persist in rigid high terrains of the Indian Himalayas. Therefore, the determination on a set of fruits was considered a reliable procedure to assess color, as the fruits start to bleach and desiccate on the tree on attaining maturity and fall off entirely as it ripens.

Using correlation analysis, we attempted to understand the relationship, if any, between these morphological characteristics and the altitude of the collection site. With an increase in altitude, plant height and canopy width were found to decrease significantly $(p>0.001)$. No significant relationship could be drawn between inter-branch distance and the altitude of the collection site. Nevertheless, the leaf length and width were negatively correlated with altitude ( $p>0.001$ ), whereas the degree of thorniness (number of thorns per $10 \mathrm{~cm}$ ) and leafiness (number of leaves per $10 \mathrm{~cm}$ ) were positively correlated with the altitude. These results also support the previous studies conducted on H. rhamnoides (Bartish et al. 2000a; Korekar 2011; Singh 2002, 2014). The variations in seabuckthorn populations reported previously have been explained due to variation by differences in physical factors across similar environments. Therefore, processes of adaptation, isolation and natural selection are possibly abundant in the species. The topography, altitude, and availability of pollens are the comprehensive factors found to be behind the variations in the morphological traits (Yao and Tigerstedt 1995; Li et al. 2007; Mangla and Tandon 2014).

Genetic distance and UPGMA cluster-based analysis of morphological features

The pair-wise genetic distance among pairs of 100 seabuckthorn collections was worked out using data recorded for twenty-seven morphological traits. The average genetic distance among Uttarakhand collections from Garhwal and Kumaon divisions was 0.57. Further, the average genetic distance between Uttarkashi, Chamoli, and Pithoragarh collections was 0.75 . The lowest genetic distance (zero) was observed between Collection ID HSY9 and HSY17, HSY21 and HSY24, HSY10 and HSY18, HSY8 and HSY16 of Uttarkashi region (Population 1), HSG46 and HSG54, HSG71, HSG77 and HSG79 of Chamoli region (Population 2 and 3). It is interesting to note here that most of the above-mentioned sample pairs showing no genetic distance were collected from the same sites. Moreover, maximum genetic distance (0.97) was observed between Collection ID HSM92 and HSM94 (Munsyari), and 
HSG41 and HSG32 (Gangotri). Overall, HSM92 and HSM100 displayed a maximum genetic distance of 0.91 in pair with HSG32 and HSB63. Using the genetic distance matrix values based on morphological characters, the 100 seabuckthorn collections were grouped into different clusters following the UPGMA cluster analysis displayed in Fig. 2. It was interesting to observe that collections from (Yamunotri and Gangotri) Uttarkashi and (Badrinath) Chamoli regions of Garhwal division (Black, red, and blue; Cluster I, III and IV) and collections from (Munsyari) Pithoragarh region of Kumaon division (Blue; Cluster II) formed two completely distinct major clusters reflecting a high level of diversity separating two geographical regions. It is quite evident from the present and previous studies also that morphological variations, to a great extent, are the result of interaction between the genotype of the individual and the abiotic factors exhibited by the environment (Assogbadjo et al. 2005).

Thus, it can be concluded from the findings of the present study that substantial variability exists in $H$. salicifolia populations in India. However, the use of molecular markers will further aid in deciphering the real differences between the collections from the different regions of Uttarakhand.

Selection of seabuckthorn genic microsatellite markers

The screening of the whole transcriptome of Seabuckthorn led to the identification of more than 8,000 microsatellite sequences in 88,297 unigenes, which offered an opportunity to enrich the limited marker resources in seabuckthorn. Clustered ESTs were also screened for the presence of microsatellites (Jain et al. 2013) and primers designed from these were also screened in the present study. Sixteen primer pairs were considered to screen 100 collections of $H$. salicifolia collections to assess the genetic diversity in relation to the geographical variability.

Validation and assessment of microsatellite markers

Frequently available sequence resources especially the genic sequences are being exploited as a fast and cost-effective approach for the development of microsatellite markers (Varshney et al. 2005). Nevertheless, the unavailability of genic sequences of seabuckthorn and other closely related species in public database prompted us to develop sequence resources in our laboratory to understand various molecular mechanisms operating in seabuckthorn enabling the plant to cope with the cold climatic conditions (Ghangal et al. 2012, 2013). EST sequencing followed by whole transcriptome sequencing generated a huge wealth of molecular resources and also offered an opportunity to isolate fast and cost-effective genic microsatellite markers (Jain et al. 2014). Validation of primer pairs from randomly selected unigenes from the whole transcriptome resulted in the amplification of $81.6 \%$ primer pairs. The possible reason behind the failure in amplification of certain microsatellite loci falling in genic regions could be either incorrect position of the primer(s) such as primer spanning across the different regions (intron-exon) or mutation(s) at primer binding sites. As splicing event removes the introns away after transcription and results in the binding of two exonic regions, primers designed for such location may sometimes give no amplification due to longdistance spanning between the priming sites (Ellis and Burke 2007).

The genetic diversity among 100 genotypes representing four geographically distinct populations were studied using fifteen microsatellite markers, which proved useful in the diversity analysis. The marker ESTSSR-25 was observed to be monomorphic in the Yamunotri population of Uttarkashi; however, it was polymorphic for the collections from Badrinath of the Chamoli region. This situation could account for varying environmental conditions prevailing at two geographical areas facilitating the natural selection of microsatellite alleles or precise fixation of the allele for a particular geographical area.

It was observed that only $15.03 \%$ of the markers developed by the screening of microsatellite enriched genomic library were polymorphic. On the other hand, $35.44 \%$ of markers developed as a result of screening genic resources were found polymorphic suggesting higher marker development efficiency in the present study compared to some of the previous studies (Tang et al. 2009; Salem et al. 2010). A possible reason behind such contradictory results could be the variation in allelic size in genic regions of seabuckthorn that might be imparting adaptation to the plant to survive in various environmental conditions. All the primer pairs were also assessed for cross-amplification and transferability in a limited number of $\mathrm{H}$. rhamnoides (on 100 collections) and $H$. tibetana (on 6 collections) collections from Drass, Kargil, and Nubra regions of the Union Territory of Ladakh, and Lahaul-Spiti and Kinnaur regions of Himachal Pradesh. All the primer pairs that produced amplification in $H$. salicifolia were cross amplified in $H$. rhamnoides and $H$. tibetana. Interestingly, all the polymorphic markers were polymorphic in H.rhamnoides but monomorphic in H. tibetana. Interestingly, the cross transferability of all H. salicifolia microsatellite markers with expected product size in other two species of seabuckthorn, namely H.rhamnoides and H.tibetana suggests that these three species are genetically close to each other. The cross transferability phenomenon observed in Hippophae species in the present study also offers an opportunity to develop microsatellite markers for other species with no prior sequence information.

Diversity analysis in $\mathrm{H}$. salcifolia collections using microsatellite markers

Distribution of microsatellite alleles

A set of microsatellite markers was employed to assess the genetic diversity prevailing among different $H$. salicifolia collections representing four diverse geographical regions, namely Yamunotri and Gangotri (Uttarkashi) and Badrinath (Chamoli) of Garhwal division, and Munsyari (Pithoragarh) of Kumaon division of Uttarakhand. A substantial variation was observed in microsatellite allele polymorphism (size range of amplicons: 110-450bp) in different collections of seabuckthorn. On application of 15 microsatellite markers on 100 collections, a total of 109 alleles were recorded, of which 78 ( $71.5 \%$ ) were found to be polymorphic. The number of effective alleles (polymorphic) ranged from 5 alleles (USSM) to 2 (GLC 11) per locus, with an average of 3 alleles per locus.

Assessment of genetic diversity of medicinally and economically important species is associated with germplasm conservation and breeding, therefore, the application of molecular markers offers an effective solution to elucidate the genetic diversity among genotypes and can prove helpful in solving 
taxonomic issues. A number of attempts have been made by researchers worldwide to assess the genetic diversity and phylogeny of Hippophae sp. (Jepsson et al.1999; Tian et al. 2004; Ruan and Li 2005; Chen et al. 2008; Raina et al. 2011; Srihari et al. 2013).

Polymorphism analysis using microsatellite markers

The PIC was calculated and the values varied from 0.486 (USSM) to 0.251 (BT 3) with a mean of 0.387 (Table 4). In a previous study, Srihari et al. (2013) reported the estimated PIC values ranging from 0.23 to 0.73 with a mean value of 0.54 in seabuckthorn. In the present study, only one marker BT3 was placed in the less informative category and the rest of the markers exhibited moderate levels of PIC.

Assessment of genetic diversity using microsatellite markers

The estimated Observed Heterozygosity $\left(\mathrm{H}_{\mathrm{o}}\right)$ varied from zero to 0.605 with an average of 0.363 per locus. The expected heterozygosity $\left(\mathrm{H}_{\mathrm{e}}\right)$ or gene diversity (Nei's) ranged from 0.48 to 0.77 with an average of 0.641 per locus (Table 4). $\mathrm{H}_{\mathrm{e}}$ for individual locus was observed to vary from 0.499 to 0.767 with an average of 0.398 per locus. Wright's Fixation Index $\left(F_{\text {is }}\right)$ and Shannon's informative index $(I)$ were calculated and ranged from 0.383 to 1.00 with an average of 0.630 , and 0.037 to 3.901 with the mean value of 0.646 per locus, respectively (Table 4).

Genetic distance and UPGMA cluster analysis using microsatellite data

Among 100 collections from the Uttarakhand region of the Indian Himalayas, maximum genetic distance (2.8) existed between collection ID HSM92and HSG35 and minimum (0) between HSM92, HSM93, HSM96, HSM97, HSM98, and HSM99 of Munsyari collections from the Pithoragarh region. Collection ID HSG29 and HSG41 from (Gangotri) Uttarkashi in Garhwal division and collection ID HSB66, HSB69, HSB89, HSB65, HSB70, and HSB86 from (Badrinath) Chamoli region also had zero genetic distance.

Based on the UPGMA analysis, seabuckthorn collections from Uttarakhand were divided into two major groups, A and B, comprising of twelve clusters (Fig. 3). Interestingly, group B consisted of nine collections (HSM92-HSM100) from Munsyari, Pithoragarh that clustered together forming one group. The major group A consisted of a total of ninety-one collections. Group A was further divided into sub-groups I and II. Subgroup II consisted of only two collections viz. HSB75 and HSB91 are both from Gangotri, Uttarkashi. The subgroup I was further subdivided into la and Ib, wherein Ib comprised of ten collections, including HSB82, HSB90, HSB79, HSB84, HSM89, HSB69, HSB66, HSB72, HSB91, and HSB75 of Gangotri region. The subgroup la consisted of nine clusters, including cluster IV-XII comprising of ninety-one collections. Clusters IV and V comprised thirteen collections only from the Badrinath region. Similarly, it was very interesting that twenty-seven collections (Cluster VI, VII, and VII) from Gangotri, Uttarkashi region and eighteen collections (Cluster XI) of Yamunotri, Uttarkashi, whereas four collections (Cluster XII) from Gangotri also clustered together. Cluster IX and X however showed mixed grouping of collections from Yamunotri and Badrinath regions. Moreover, the majority of samples collected from one collection site got clustered together depicting the similarity between the ecotypes coming from one micro-environment. Overall, it was very interesting to note that the collections from four different regions showed their respective region-specific genetic identity.

AMOVA results of our study showed the highest genetic variation (78\%) among the individuals across populations, $7 \%$ of the total genetic variation among the individuals within populations, and only $15 \%$ was among the population (Table 5). To measure the genetic differentiation of populations, the $F_{\mathrm{ST}}$ and $F_{\mathrm{IS}}$ were also calculated and the values were low, $(0.263$ and 0.190$)$, whereas $F_{\mathrm{IT}}$ values were a little higher but still low (0.308) (Table 5). Nei's genetic similarity matrix was calculated following Nei and Li (1979) from sixteen microsatellite markers using Unweighted Pair Group Method with Arithmetic mean (UPGMA) to study the overall genetic relationship (Table 6). The clustering pattern of four populations based on Nei's genetic differences revealed that population 4 (Pithoragarh) was out-grouped showing $40 \%$ of the genetic difference to all other populations, which grouped at $7 \%$ of genetic differences. The observations were based on the combined marker analysis. Overall, the four populations of $H$. salicifolia revealed moderate levels of genetic diversity among themselves. The possible reason behind such clustering could be habitat fragmentations due to vast geographical barriers. Similar observations of the clustering pattern of seabuckthorn collections according to their geographical affiliations were also reported earlier by Srihari et al. (2013).

Comparative estimation of diversity revealed by microsatellite markers and morphometric characters

It was observed that assessment of diversity in $\mathrm{H}$. salicifolia using molecular markers was more efficient in comparison to that obtained by using morphological characteristics of the plant. This could be well illustrated by collection pairs showing no genetic distance such as HSY9, HSY17, HSY21, and HSY24, HSY8, HSY10, and HSY16on the basis of morphological characters, which could be differentiated following molecular marker data. With the advent of advancing softwares, the availability of genic sequences and in silico mining of microsatellite sites from these resources have provided researchers with great opportunities for marker development. Utilizing these microsatellite markers, the presence of substantial genetic diversity was shown to exist in seabuckthorn collections. Therefore, on the basis of the prevalence of high genetic diversity in seabuckthorn, we suggest that there is ample scope of improvement in seabuckthorn cultivars through focused breeding and conservation programs.

\section{Conclusion}

The present study on the assessment of genetic diversity in a large collection of $H$. salcifolia from the Uttarakhand region of the Indian Himalayas generates important data for the first time for this unexplored species with significant economic and ecological value. The environmental variations prevailing in the areas covered in the study have a determining effect on genetic diversity as revealed by the data from 27 morphological characteristics and16 microsatellite markers. Overall, it was evident that molecular markers are more efficient tools to assess the genetic variability existing in 
seabuckthorn populations in comparison to morphological characters. Our findings suggest that a significant level of diversity is available in seabuckthorn that could offer ample scope of improvement in seabuckthorn through focused breeding and conservation programs that can be facilitated by exploitation of the microsatellite marker-based resources.

\section{Declarations}

Author contributions PCS designed the study, planned experiments, and finalized the manuscript. PC collected samples, conducted experiments, performed data analysis, and prepared the initial draft. All authors read and approved the final manuscript.

Funding No funding was received for conducting this study.

Ethics Approval This article does not contain any studies with human and/or animal participants performed by any of the authors.

Informed Consent Not applicable.

Acknowledgments PC acknowledges the award of a Short Term Research Fellowship by Guru Gobind Singh Indraprastha University, New Delhi, and the useful suggestions by Mrs. Sugandh Singh in the use of softwares for the analysis of diversity.

Conflict of interest The authors declare no conflict of interest.

\section{References}

1. Akulinin IA (1958) Using sea-buckthorn oil in treating burns. Sov Med 11:137-138

2. Assogbadjo AE, Sinsin B, Van Damne P (2005) Caractères morphologiques et production des capsules de baobab (Adansonia digitata L.) au Bénin. Fruits 60:327-340

3. Bartish IV, Jeppsson N, Nybom H (1999) Population genetic structure in the dioecious pioneer plant species Hippophae rhamnoides investigated by random amplified polymorphic DNA (RAPD) markers. Mol Ecol 8:791-802

4. Berding N, Roach BT (1987) Germplasm collection, maintenance, and use. In: DJ Heinz (Ed.), Sugarcane Improvement Through Breeding. Elsevier, New York, pp. 143:210

5. Chen G, Wang Y, Korpelsinen H, Li C (2008) Genetic diversity of Hippophae rhamnoides populations at varying altitude in Wolong natural reserve of China as revealed by ISSR markers. Silvae Genet 57:29-36

6. Crozier YC, Jia XC, Yao JY, Field AR, Cook JM, Crozier RH (2007) Microsatellite primers for Ficus racemosa and Ficus rubiginosa. Mol Ecol Notes 7:5759

7. Doyle JJ, Doyle JL (1990) Isolation of plant DNA from fresh tissue. Focus 12:13-15.

8. Dwivedi SK, Stobdan T, Singh SB (2009) Seabuckthorn in Ladakh. In: Seabuckthorn Hippophae spp.: The golden bush. SSPH Publisher, Delhi, India pp 35-51

9. Ellis JR, Burke JM (2007) EST-SSRs as a resource for population genetic analyses. Heredity 99:125-132

10. Ge X, Shi G, Zhang Y (1985) Application of sea-buckthorn in medicine. Shanxi Med Res 2:9-14

11. Grover A, Sharma PC (2016) Development and use of molecular markers: past and present. Crit Rev Biotechnol 36:290-302

12. Grover A, Aishwarya V, Sharma PC (2012) Searching microsatellite in DNA sequences: approaches used and tools developed. Physiol Mol Biol Plants 18:11-19

13. Hammer $\emptyset$, Harper DAT, Ryan PD (2010) PAST: Paleontological statistics software package for education and data analysis. Palaeontol Electron $4(1): 9$

14. Jain A (2015) Analysis of microsatellite polymorphism in relation to geographical distribution and adaptation of seabuckthorn in India. Ph. D. thesis, Guru Gobind Singh Indraprastha University, Delhi.

15. Jepsson N, Bartish IV, Persson HA (1999) DNA analysis as a tool in seabuckthorn breeding. ASHS Press, Alexandria, VA pp $338-341$

16. Korekar G, Stobdan T, Singh H, Chaurasia OP, Singh SB (2011) Phenolic content and antioxidant capacity of various solvent extracts from seabuckthorn (Hippophae rhamnoides L.) fruit pulp, seeds, leaves and stem barks. Acta Ailmentaria 40:449-458

17. Li K, Wu W, Zheng Y, Dai Y, Xiang L, Liao K (2009) Genetic diversity of Fritillaria from Sichuan province based on ISSR. Zhongguo Zhong Yao ZaZhi 34:2149-2154

18. Li C, Xu G, Zang R, Korpelainen H, Berninger F (2007) Sex-related differences in leaf morphological and physiological responses in Hippophae rhamnoides along an altitudinal gradient. Tree Physiol 27:399-406

19. Lian YS, Chen XL, Sun K, Ma R (2003) A new subspecies of Hippophae (Elaeagnaceae) from China. Novon 13:200-202

20. Lian YS, Chen XL (2000) The regular patterns of distribution on the natural components in plants of the genus Hippophae L. J. North Norm Univ 36:113-128

21. Lu R (1992) Sea buckthorn - A multipurpose plant species for fragile mountains. ICIMOD Occasional Paper No. 20. Kathmandu, Nepal, pp 26 
22. Ma KH, Dixit A, Kim YC, Lee DY, Kim TS, Cho EG, Park YJ (2007) Development and characterization of new microsatellite markers for ginseng (Panax ginseng C. A. Meyer). Cons Gen 8:1507-1509

23. Mangla Y, Tandon R (2014) Pollination ecology of Himalayan seabuckthorn, Hippophae rhamnoides L. (Elaeagnaceae). Curr Sci 106:1731-1735

24. Nawaz MA, Krutovsky KV, Mueller M, Gailing O, Khan AA, Buerkert A, Wiehle M (2018) Morphological and genetic diversity of Seabuckthorn (Hippophae rhamnoides L.) in the Karakoram Mountains of Northern Pakistan. Diversity https://doi.org/10.3390/d10030076

25. Nei M, Li WH (1979) Mathematical model for studying genetic variation in terms of restriction endonucleases. Proc Natl Acad Sci USA 76:5269-5273

26. Peakall R, Smouse PE (2012) GenAlEx 6.5: genetic analysis in Excel. Population genetic software for teaching and research-an update. Bioinformatics 28:2537-2539

27. Raina SN, Jain S, Sehgal D, Kumar A, Dar TH, Bhat V, Pandey V, Vaishnavi S, Bhargav A, Singh V, Rani V, Tandon R, Tewari M, Mahmoudi A (2011) Diversity and relationships of multipurpose seabuckthorn (Hippophae L.) germplasm from the Indian Himalayas as assessed by AFLP and SAMPL markers. Genet Resour Crop Evol 59:1033-1053

28. Roldan-Ruiz I, Van Euwijk FA, Gilliland TJ, Dubreuil P, Dillmann C, De Loose M, Baril CP (2001) A Comparative study of molecular and morphological methods of describing relationships between perennial rye grass (Lolium perenneL.) varieties. Theor Appl Genet 103: 1138-1150

29. Rousi A (1971) The genus Hippophae L. A taxonomic study. Ann Bot Fennici 8: 177-227

30. Rozen SG, Untergasser A, Cutcutache I, Koressaar T, Ye J, Faircloth BC, Remm M (2012) Primer3-new capabilities and interfaces. Nucleic Acids Res 40:e115

31. Ruan C, Li D (2005) AFLP fingerprinting analysis of some cultivated varieties of sea buckthorn (Hippophae rhamnoides). J Genet 84: $311-316$

32. Salem KF, Varshney RK, Röder M, Sand Börner A (2010) EST-SSR based estimates on functional genetic variation in a barley (Hordeum vulgare L.) collection from Egypt. Genet Resour Crop Evol 57: 515-521

33. Singh V (2014) New findings on morphological variations and co-relationship of characteristics among various natural populations of seabuckthorn (Hippophae L.) growing in 5 districts of Himachal Pradesh, north-west Himalayas, India. In: Mörsel JT, Zubrarev Y, Eagle D (Eds) Seabuckthorn research for a promising crop: A look at recent developments in cultivation, breeding, technology, health and environment. Books on Demand, Norderstedt pp 139-162

34. Singh V, Kallio H, Yang B (2008) Seabuckthorn (Hippophae L.): a multipurpose wonder plant (Vol. 3). Daya Publishing House, New Delhi, India

35. Singh R, Dwivedi SK, Mishra SN (2005) Morphology and distribution of Seabuckthorn (Hippophae rhamnoides L.) population of cold arid Ladakh (India) using RAPD markers. Curr Sci 91:1321-1322

36. Singh R, Dwivedi SK, Raut B, Mishra SN (2003) Ethnobotany of Hippophae'seabuckthorn' in Ladakh. Ethnobotany 15:1-5

37. Singh V (2002) Studies on genetic diversity and improvement of seabuckthorn a multipurpose plant of cold desert Himalayas. Envis Bulletin 110:8-9

38. Srihari JM, Verma B, Kumar N, Chahota RK, Singh V, Rathour R, Singh SK, Sharma SK, Sharma TR (2013) Analysis of molecular genetic diversity and population structure in sea buckthorn (Hippophae ssp L.) from north-western Himalayan region of India. J Med Plant Research 7:3183-3196

39. Sun K, Chen W, Ma R, Chen N, Li A, Ge S (2006) Genetic variation in Hippophae rhamnoides ssp. Sinensis (Elaeagnaceae) Revealed by RAPD markers. Biochem Gen 44:5-6

40. Suryakumar G, Gupta A (2011) Medicinal and therapeutic potential of seabuckthorn (Hippophae rhamnoides L.). J Ethanopharmacol 138:268-278

41. Tang S, Okashah RA, Cordonnier-Pratt MM, Pratt LH, Johnson VE, Taylor CA, Arnold ML, Knapp SJ (2009) EST and EST-SSR marker resources for Iris. BMC Plant Biol 9:72

42. Teng BS, Lu YH, Wang ZT, Tao XY, Wei DZ (2006) In vitro anti-tumor activity of isorhamnetin isolated from Hippophae rhamnoides L. against BEL7402 cells. Pharmacol Res 54: 186-194

43. Tian CJ, Lei YD, Shi SH, Nan P, Chen JK, Zhong Y (2004) Genetic diversity of sea buckthorn (Hippophae rhamnoides) populations in northeastern and northwestern China as revealed by ISSR markers. New Forests 27:229-237

44. Varshney RK, Graner A, Sorrells ME (2005) Genic microsatellite markers in plants: features and applications. Trends Biotechnol 23:48-55

45. Yao YM, Tigerstedt PMA (1993) Isozyme studies of genetic diversity and evolution in Hippophae. Genet Resour Crop Evol 40:153-164

46. Yeh FC, Boyle TJB (1997) Population genetic analysis of co-dominant and dominant markers and quantitative traits. Belgian J Bot 129:157-163

47. Zhao Y, Fuheng W (1997) Seabuckthorn flavonoids and their medical value. Hippophae 10: 39-41

\section{Tables}

Table 1 List of $H$. salcifolia populations used in the present study 


\begin{tabular}{|c|c|c|c|c|c|c|c|c|}
\hline Region & Collection Id & Location & Latitude & Longitude & $\begin{array}{l}\text { Altitude } \\
(\mathrm{m})\end{array}$ & $\begin{array}{l}\text { Temperature } \\
\left({ }^{\circ} \mathrm{C}\right)\end{array}$ & Soil type & Habitat \\
\hline Yamunotri & HSY1-HSY6 & $\begin{array}{l}\text { Hanuman- } \\
\text { Chatti }\end{array}$ & $\begin{array}{l}\mathrm{N} \\
32 \varangle 01.827^{\prime}\end{array}$ & $\begin{array}{l}\text { E } \\
078 \varangle 00.379^{\prime}\end{array}$ & 2529 & 9 & Silty-loam & Road-side \\
\hline - & HSY7-HSY 12 & Krishna-Chatti & $\begin{array}{l}\mathrm{N} \\
32 \searrow 31.172^{\prime}\end{array}$ & $\begin{array}{l}\mathrm{E} \\
078 \otimes 23.906\end{array}$ & 2600 & 6 & Silty loam & Road-side \\
\hline- & HSY 13- HSY 18 & Phool-Chatti & $\begin{array}{l}\mathrm{N} \\
30 \otimes 52.606^{\prime}\end{array}$ & $\begin{array}{l}\text { E } \\
078 \otimes 24.846^{\prime}\end{array}$ & 2623 & 5 & Silty loam & Road-side \\
\hline - & HSY 19- HSY 22 & Janki-Chatti & $\begin{array}{l}\mathrm{N} \\
30 \otimes 97.027^{\prime}\end{array}$ & $\begin{array}{l}\text { E } \\
078 \otimes 43.075^{\prime}\end{array}$ & 2650 & 2 & Silty loam & Road-side \\
\hline - & HSY 23- HSY 26 & Kharsali & $\begin{array}{l}\mathrm{N} \\
30 \otimes 97.027^{\prime}\end{array}$ & $\begin{array}{l}\text { E } \\
078 \otimes 43.075^{\prime}\end{array}$ & 2680 & -1 & Silty loam & Village \\
\hline Gangotri & HSYG27- HSYG30 & Dharali & $\begin{array}{l}\mathrm{N} \\
30 \otimes 53.373^{\prime}\end{array}$ & $\begin{array}{l}\mathrm{E} \\
078 \otimes 25.850^{\prime}\end{array}$ & 2620 & 12 & Silty loam & River-bank \\
\hline- & HSYG 31- HSYG 34 & Harsil & $\begin{array}{l}\mathrm{N} \\
31 \otimes 02.504\end{array}$ & $\begin{array}{l}\text { E } \\
078 \otimes 25.850^{\prime}\end{array}$ & 2620 & 15 & Silty loam & River-bank \\
\hline & HSYG 35- HSYG 40 & Jaspur & $\begin{array}{l}\mathrm{N} \\
30 \otimes 56.158^{\prime}\end{array}$ & $\begin{array}{l}\text { E } \\
078 \varangle 42.741^{\prime}\end{array}$ & 3300 & 10 & Silty loam & $\begin{array}{l}\text { Mountain- } \\
\text { side }\end{array}$ \\
\hline - & HSYG 41- HSYG 42 & Sukki & $\begin{array}{l}\mathrm{N} \\
30 \otimes 56.158^{\prime}\end{array}$ & $\begin{array}{l}\text { E } \\
078 \varangle 42.741^{\prime}\end{array}$ & 3200 & 8 & Silty loam & Road-side \\
\hline - & HSYG 43- HSYG 50 & Kopang & $\begin{array}{l}\mathrm{N} \\
31 \otimes 02.265^{\prime}\end{array}$ & $\begin{array}{l}\mathrm{E} \\
078 \otimes 41.796\end{array}$ & 2400 & 19 & Silty loam & Road-side \\
\hline- & HSYG 51- HSYG 60 & Maneri & $\begin{array}{l}\mathrm{N} \\
30 \otimes 53.135^{\prime}\end{array}$ & $\begin{array}{l}\text { E } \\
078 \varangle 41.796\end{array}$ & 2648 & 19 & Silty loam & River-side \\
\hline Badrinath & HSYB61- HSYB 64 & $\begin{array}{l}\text { Hanuman- } \\
\text { Chatti }\end{array}$ & $\begin{array}{l}\mathrm{N} \\
30 \otimes 53.135^{\prime}\end{array}$ & $\begin{array}{l}\text { E } \\
078 \llbracket 41.796\end{array}$ & 2788 & 10 & $\begin{array}{l}\text { Fine } \\
\text { Loamy }\end{array}$ & Road-side \\
\hline - & HSYB 65- HSYB 70 & Govind-Ghat & $\begin{array}{l}\mathrm{N} \\
30 \otimes 53.135^{\prime}\end{array}$ & $\begin{array}{l}\mathrm{E} \\
078 \otimes 43.075^{\prime}\end{array}$ & 2751 & 7 & $\begin{array}{l}\text { Fine } \\
\text { Loamy }\end{array}$ & Road-side \\
\hline- & HSYB 71- HSYB 78 & Lambagad & $\begin{array}{l}\mathrm{N} \\
30 \otimes 53.135^{\prime}\end{array}$ & $\begin{array}{l}\text { E } \\
078 \varangle 41.796\end{array}$ & 2881 & 6 & $\begin{array}{l}\text { Fine } \\
\text { Loamy }\end{array}$ & Road-side \\
\hline - & HSYB 79- HSYB 84 & Mana & $\begin{array}{l}\mathrm{N} \\
30 \otimes 77.265^{\prime}\end{array}$ & $\begin{array}{l}\text { E } \\
079 \varangle 49.536\end{array}$ & 3200 & 3 & $\begin{array}{l}\text { Fine } \\
\text { Loamy }\end{array}$ & $\begin{array}{l}\text { Mountain- } \\
\text { side }\end{array}$ \\
\hline - & HSYB 85- HSYB 91 & Loharinag-Pala & $\begin{array}{l}\mathrm{N} \\
30 \otimes 53.135^{\prime}\end{array}$ & $\begin{array}{l}\text { E } \\
078 \otimes 41.796\end{array}$ & 2751 & 10 & $\begin{array}{l}\text { Fine } \\
\text { Loamy }\end{array}$ & River-bank \\
\hline Pithoragarh & $\begin{array}{l}\text { HSYM 92- HSYM } \\
100\end{array}$ & Munsyari & $\begin{array}{l}\mathrm{N} \\
30 \otimes 03.910^{\prime}\end{array}$ & $\begin{array}{l}\text { E } \\
080 \otimes 14.360^{\prime}\end{array}$ & 2162 & 4 & $\begin{array}{l}\text { Fine } \\
\text { Loamy }\end{array}$ & Nursery \\
\hline
\end{tabular}

HSY: represents collections of $H$. salicifolia from Yamunotri, Uttarkashi; HSG: represents collections of $H$. salicifolia from Gangotri, Uttarkashi; HSB: represents collections of $H$. salicifolia from Badrinath, Chamoli; HSM: represents collections of $H$. salicifolia from Munsyari, Pithoragarh

Table 2 Details of primers of the microsatellite markers used in the present study 


\begin{tabular}{|c|c|c|c|c|c|}
\hline Primer Id & Primer sequence 5'-3 & Microsatellite repeat & $\operatorname{Tm}(\mathbb{C C})$ & Location & Size range (bp) \\
\hline \multirow[t]{2}{*}{ GLC 2-6 } & F: GGT ATG TAG ATA AGG CCA CAA & \multirow{2}{*}{$(\mathrm{CT})_{7}$} & \multirow[t]{2}{*}{56.0} & \multirow[t]{2}{*}{ Anonymous } & \multirow[t]{2}{*}{$160-185$} \\
\hline & R: CCA ATG ATA TAA ACC CTC CAC & & & & \\
\hline \multirow[t]{2}{*}{ GLC 2-5 } & F: GTG ATG GCC CTA GTT ATA GA & \multirow[t]{2}{*}{$(\mathrm{GA})_{13}$} & \multirow[t]{2}{*}{53.0} & \multirow[t]{2}{*}{ Anonymous } & \multirow[t]{2}{*}{$360-380$} \\
\hline & R: CGT AAT ATC CAA ACA GAC CA & & & & \\
\hline \multirow[t]{2}{*}{ GLC 11} & F: ATT CGA AGA AGC AGG GAT A & \multirow[t]{2}{*}{$(\mathrm{GA})_{12}$} & \multirow[t]{2}{*}{54} & \multirow[t]{2}{*}{ Anonymous } & \multirow[t]{2}{*}{$320-350$} \\
\hline & R: GCA ATG AAG TCC TTG TTA TC & & & & \\
\hline \multirow[t]{2}{*}{ USMM } & F: AAG GAT GTG GTC GAT CCA AG & \multirow[t]{2}{*}{$(\mathrm{TTC})_{10}$} & \multirow[t]{2}{*}{54.0} & \multirow[t]{2}{*}{ CDS } & \multirow[t]{2}{*}{$160-190$} \\
\hline & R: GTT TGC AGG CAT TCC TTT GT & & & & \\
\hline \multirow[t]{2}{*}{ USMM 1} & F: GGC GAA ACT TGA CTT GTT GC & \multirow[t]{2}{*}{$(\mathrm{TAC})_{16}$} & \multirow[t]{2}{*}{55.0} & \multirow[t]{2}{*}{ 3'UTR } & \multirow[t]{2}{*}{$180-220$} \\
\hline & R: ACC GAT CAA TAC CGT TCT GC & & & & \\
\hline \multirow[t]{2}{*}{ USMM 5} & F: TTC GAT CGG ATA AGG TCA TTG & \multirow[t]{2}{*}{$(\mathrm{AC})_{9}(\mathrm{AT})_{6}$} & \multirow[t]{2}{*}{56.0} & \multirow[t]{2}{*}{ CDS } & \multirow[t]{2}{*}{$190-240$} \\
\hline & R: GCA GTC GAG GAG GTT TGA AG & & & & \\
\hline \multirow[t]{2}{*}{ USMM 7} & F: TCG CCG TCT GTT TCA GAT AA & $(A G)_{18}$ & 50.0 & 3'UTR & $180-210$ \\
\hline & R: GCT GAT CCA ACG GTC TCA TT & & & & \\
\hline USMM 24 & F: TAG CAT TGC AGG CTC AGA GA & $(A G)_{11}$ & 55.0 & 3'UTR & $240-270$ \\
\hline & R: ATC CGT GGT TAA GGT TGC AC & & & & \\
\hline ESTSSR 25 & F: GTA CTG TGA CCA CGC TGC & $(\mathrm{AG})_{8}$ & 53.0 & 3'UTR & $280-320$ \\
\hline & R: GGG TTC AAA GTA ATG GCA AG & & & & \\
\hline BT-1 & F:TTC CCT GGT GAA CAA CCC CA & $(\mathrm{AAGA})_{7}$ & 48 & Anonymous & $150-180$ \\
\hline & R:ACT GTT GGC CCA AGT AAG CCT & & & & \\
\hline BT-2 & F: GGC GAA ACT TGA CTT GTT GCC CT & $(\mathrm{TAC})_{16}$ & 54 & Anonymous & $120-150$ \\
\hline & R: GGG TTC CAC CAC CAA AGC AAA CCA & & & & \\
\hline BT-3 & F:CAG AGT GGA GCG TCC GCG TG & $(\mathrm{TAA})_{11}$ & 48 & Anonymous & $180-200$ \\
\hline & R: GGC ACA GTA ACA CTA AGC ACC CCA & & & & \\
\hline BT-4 & F:AGG GGA CTT AAG AGC AGA GGC CA & $(\mathrm{TTTA})_{5}$ & 48.7 & Anonymous & $150-180$ \\
\hline & R: CAT GCT CTG CAA CTT TTG GTT TCG T & & & & \\
\hline BT-5 & F:TTG GTG CTC GAG CTG TTC GG & $(\mathrm{CAA})_{9}$ & 52 & Anonymous & $140-190$ \\
\hline & R: AGC ACG GAG GTG GAA AAG CC & & & & \\
\hline BT-6 & F:GGC CTA CTC CAG GTG TTG CAC & $(\mathrm{TCA})_{10}$ & 48.3 & Anonymous & $120-150$ \\
\hline & R:CCA ACC ATG GCC AGA AGG CA & & & & \\
\hline
\end{tabular}

GLC series marker: resulted from microsatellite enriched genomic library; ESTSSR marker: resulted from EST database screening; USSM and BT series

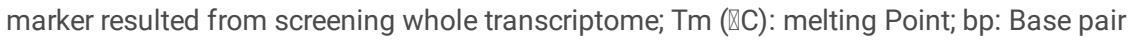

Table 3 Morphological characteristics (mean values) of $H$. salicifolia collections 


\begin{tabular}{|c|c|c|c|c|c|c|c|c|c|c|c|c|}
\hline \multirow[t]{2}{*}{ Region } & \multirow[t]{2}{*}{ Population } & \multicolumn{3}{|c|}{ Dendrometry } & \multicolumn{2}{|l|}{ Leaf } & \multicolumn{3}{|l|}{ Thorn } & \multicolumn{3}{|l|}{ Fruit } \\
\hline & & $\begin{array}{l}\text { Plant } \\
\text { height } \\
(\mathrm{cm})\end{array}$ & $\begin{array}{l}\text { Canopy } \\
\left(\mathrm{m}^{2}\right)\end{array}$ & $\begin{array}{l}\text { Interbranch } \\
\text { distance } \\
(\mathrm{cm})\end{array}$ & $\begin{array}{l}\text { No. of } \\
\text { leaves/10 } \\
\text { cm } \\
\text { branch }\end{array}$ & $\begin{array}{l}\text { Length } \\
\text { to } \\
\text { width } \\
\text { ratio }\end{array}$ & $\begin{array}{l}\text { Leaf } \\
\text { on } \\
\text { thorns }\end{array}$ & $\begin{array}{l}\text { No. of } \\
\text { thorns }\end{array}$ & $\begin{array}{l}\text { Length } \\
\text { of } \\
\text { thorns } \\
(\mathrm{mm})\end{array}$ & $\begin{array}{l}\text { Length } \\
\text { to } \\
\text { width } \\
\text { ratio }\end{array}$ & $\begin{array}{l}20- \\
\text { berry } \\
\text { Wt. (g) }\end{array}$ & $\begin{array}{l}\text { No. of } \\
\text { berried/10 } \\
\text { cm } \\
\text { branch }\end{array}$ \\
\hline Uttarkashi & Yamunotri & 133 & 2.54 & 16.9 & 32 & 7.25 & 0 & 0 & - & 1.9 & 5.18 & 68 \\
\hline Chamoli & Badrinath & 257 & 2.5 & 24.6 & 94 & 7.5 & 3 & 7 & 2.9 & 1.8 & 3.28 & 42 \\
\hline \multirow[t]{3}{*}{ Pithoragarh } & Munsyari & 283 & 2.29 & 11.21 & 72 & 6.9 & - & - & - & 1.4 & 3.10 & 61 \\
\hline & $p$-value & $<0.001$ & $<0.001$ & $<0.001$ & $<0.001$ & $<0.001$ & $<0.001$ & $<0.001$ & $<0.001$ & $<0.001$ & $<0.001$ & $<0.001$ \\
\hline & $\begin{array}{l}\text { Grand } \\
\text { mean }\end{array}$ & 290 & 8.21 & 18.7 & 69.5 & 24.1 & 4 & 4.5 & 1.1 & 2.8 & 3.7 & 51.5 \\
\hline
\end{tabular}

Table 4 Summary of genetic diversity parameters in $\mathrm{H}$. salicifolia collections using sixteen microsatellite markers

\begin{tabular}{|lllllll|}
\hline Primer & PIC & $\mathrm{N}_{\mathrm{A}}$ & $\mathrm{H}$ V & $\mathrm{H}_{\mathrm{e}}$ & $\mathrm{I}$ & $\mathrm{F}_{\text {is }}$ \\
\hline ESTSSR 25 & 0.328 & 4 & 0.414 & 0.536 & 3.901 & 0.680 \\
\hline USMM & 0.44 & 5 & 0.478 & 0.767 & 3.727 & 0.467 \\
\hline USMM 1 & 0.395 & 4 & 0.471 & 0.712 & 3.619 & 0.760 \\
\hline USMM 5 & 0.486 & 4 & 0.483 & 0.619 & 3.850 & 0.539 \\
\hline USMM 7 & 0.381 & 3 & 0.446 & 0.573 & 3.682 & 0.732 \\
\hline USMM 24 & 0.382 & 3 & 0.592 & 0.618 & 3.547 & 0.098 \\
\hline GLC 2-6 & 0.461 & 3 & 0.51 & 0.657 & 1.296 & 0.790 \\
\hline GLC 2-5 & 0.379 & 3 & 0 & 0.642 & 1.032 & 1 \\
\hline GLC 11 & 0.341 & 2 & 0.605 & 0.517 & 0.837 & 0.653 \\
\hline BT-1 & 0.387 & 3 & 0.019 & 0.499 & 3.427 & 0.704 \\
\hline BT-2 & 0.346 & 3 & 0.265 & 0.585 & 2.828 & 0.546 \\
\hline BT-3 & 0.251 & 2 & 0.403 & 0.495 & 3.697 & 0.183 \\
\hline BT-4 & 0.496 & 4 & 0.079 & 0.499 & 0.692 & 0.845 \\
\hline BT-5 & 0.307 & 3 & 0.376 & 0.643 & 2.061 & 0.478 \\
\hline BT-6 & 0.45 & 3 & 0.315 & 0.517 & 2.013 & 0.780 \\
\hline
\end{tabular}

PIC: Polymorphic Information Content; $\mathrm{N}_{\mathrm{a}}$ : Number of alleles; $\mathrm{H}$ : Observed heterozygosity; $\mathrm{H}_{\mathrm{e}}$ : Nei Expected heterozygosity; I: Shannon Information Index; $\mathrm{F}_{\mathrm{is}}$ : Wright's Fixation Index

Table 5 Hierarchical analysis of molecular variance in four $H$. salicifolia populations

\begin{tabular}{|lcccccccc|}
\hline Source & df & SS & MS & E $_{\text {st }}$ Var. & $\%$ Total Variance & $F_{\text {ST }}$ & $F_{\text {IS }}$ & $F_{\text {IT }}$ \\
\hline Among pops & 3 & 471.65 & 182.82 & 18.39 & $78 \%$ & & & \\
\hline Among individual Pops & 86 & 1306.23 & 97.99 & 19.23 & $7 \%$ & $0.263^{\star \star \star}$ & $0.190^{\star \star \star}$ & $0.308^{\star \star \star}$ \\
\hline Within Pops & 99 & 1692.29 & 73.71 & 62.78 & $15 \%$ & & & \\
\hline Total & 103 & 3470.17 & 354.52 & 100.4 & $100 \%$ & & \\
\hline
\end{tabular}

Pops-Population; df- Degree of Freedom; SS- Standard Significance; MS-Mean Significance; Est Var.- Estimated Variation; $F_{\mathrm{ST}} F_{\mathrm{IS}}$ and $F_{\mathrm{IT}}$-individual, inter-

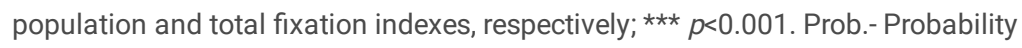

Table 6 Nei's genetic similarity (above diagonal) and difference (below diagonal) of four populations of $H$. salicifolia 


\begin{tabular}{|lllll|}
\hline Region & Population 1 & Population 2 & Population 3 & Population 4 \\
\hline Population 1 & - & 0.926 & 0.817 & 0.792 \\
\hline Population 2 & 0.043 & - & 0.828 & 0.737 \\
\hline Population 3 & 0.074 & 0.169 & - & 0.712 \\
\hline Population 4 & 0.415 & 0.339 & 0.089 & - \\
\hline
\end{tabular}

Population 1: Yamunotri (Uttarkashi); Population 2: Gangotri (Uttarkashi); Population 3: Badrinath (Chamoli); Population 4: Munsyari (Pithoragarh)

\section{Figures}

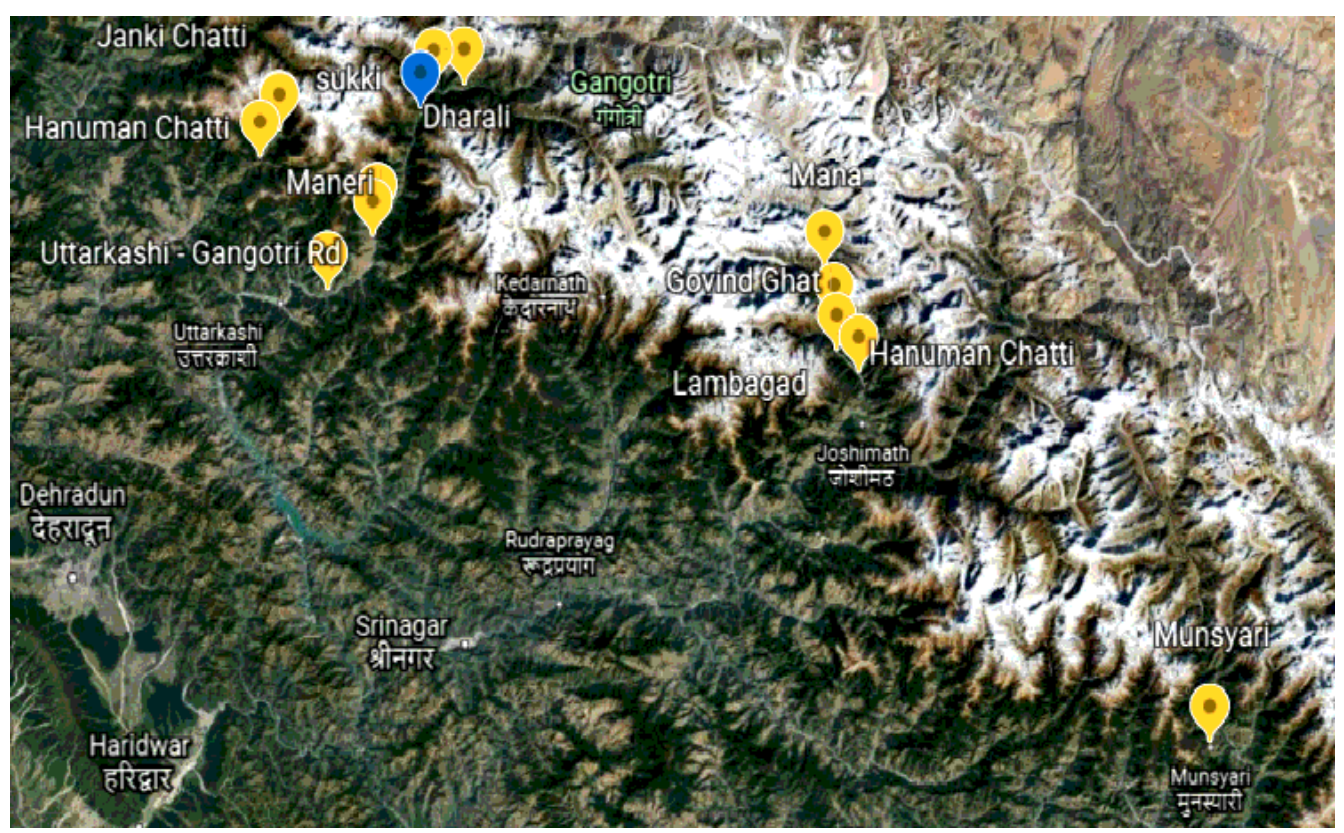

Figure 1

Collection sites from Uttarakhand region indicated by yellow pointers (Map adopted from Google earth feature) 


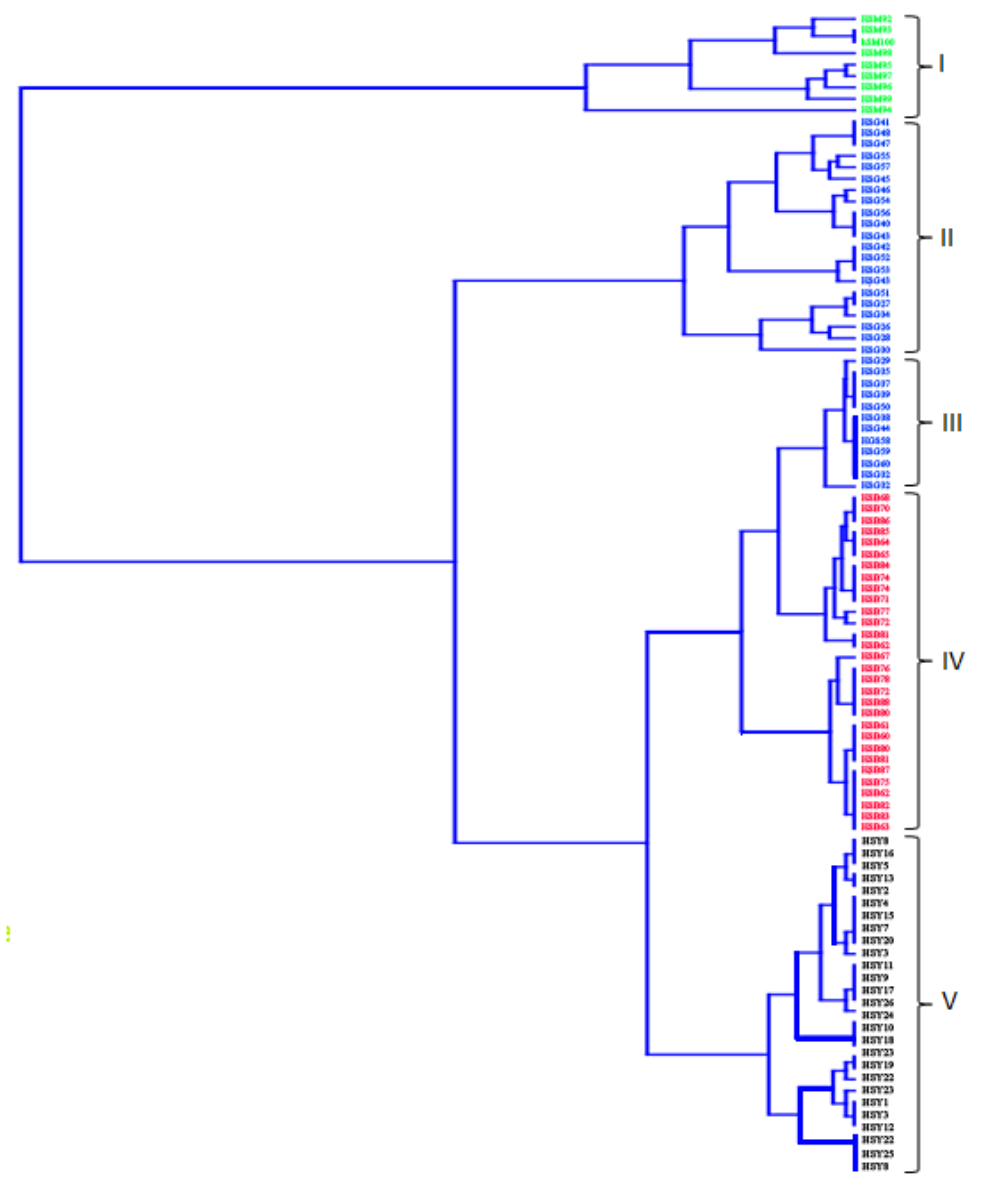

Figure 2

Dendrogram generated using Jaccard's coefficient and UPGMA cluster analysis in PAST software for 100 Hippophae salicifolia collections analyzed considering twenty-seven morphological traits

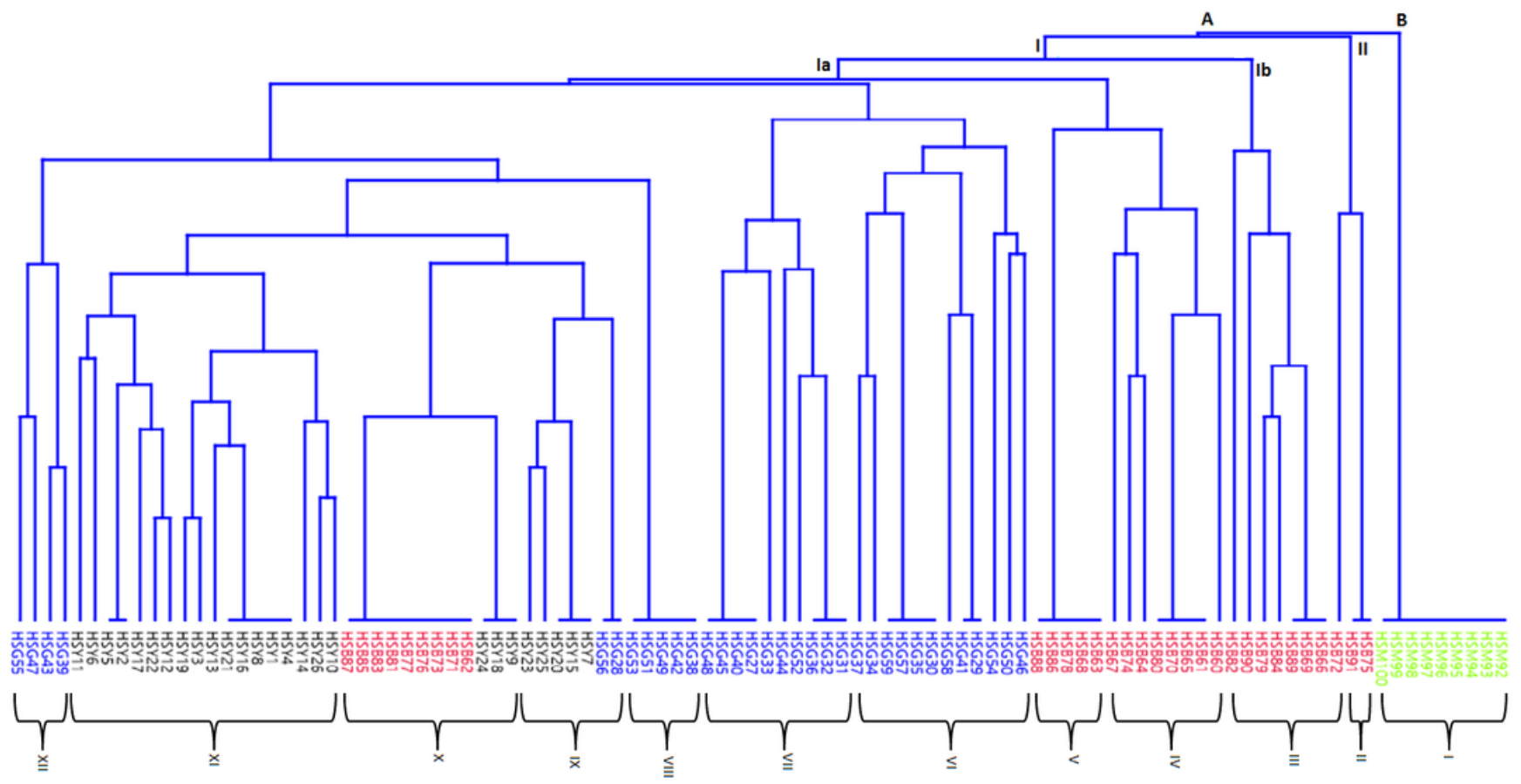

Page 13/14 
Figure 3

Dendrogram generated using Jaccard's coefficient and UPGMA cluster analysis in PAST software for 100 Hippophae salicifolia collections analyzed using sixteen microsatellite-markers

\section{Supplementary Files}

This is a list of supplementary files associated with this preprint. Click to download.

- SupplementaryFileGRCE.pdf 